\title{
Criação e implantação do Curso de Graduação em Geologia na Universidade Federal do Espírito Santo
}

\author{
Paulo de Tarso Ferro de Oliveira Fortes \\ Universidade Federal do Espírito Santo - Campus de Alegre \\ Departamento de Geologia - Alto Universitário s/n - Caixa \\ Postal 16 - Alegre - ES - 29.500-000 \\ paulo.fortes@ufes.br
}

\begin{abstract}
CREATION AND IMPLEMENTATION OF THE UNDERGRADUATE COURSE IN GEOLOGY AT THE FEDERAL UNIVERSITY OF ESPÍRITO SANTO. The undergraduate degree in geology at the Federal University of Espirito Santo was created in 2005 and the first class of students entered by 2006. The initial phase of deployment is considered completed in 2011, after graduation of the first class of geologists and the course recognition by the Education Ministery. The total course load is 4,410 hours, along five years-time; 40 places are offered annually, performing a candidate/vacancy ratio around nine. About 200 students are enrolled in six classes, coming mainly from the regions of Greater Vitória, Polo Cachoeiro and Caparao (Espirito Santo State) and from Minas Gerais and Rio de Janeiro states. The course accounts with 12 teachers and a small administrative staff; some basic laboratories guarantee the required activities and fieldwork. The current operating conditions suggest that the future self-evaluation and updating and revision of the educational project shall assist in the consolidation of the undergraduate course both at state and regional levels. Citation: Fortes P.T.F.0. 2013. Criação e implantação do Curso de Graduação em Geologia na Universidade Federal do Espírito Santo. Terræ Didática, 9(1):2-13. <http://www.ige.unicamp.br/terraedidatica/> .
\end{abstract}

KEYWORDS: Geology, undergraduate degree course, Universidade Federal do Espirito Santo, Brazil

RESUMO A fase inicial do curso de graduação em Geologia da Universidade Federal do Espírito Santo pode ser considerada concluída após as etapas de criação, em 2005, e de implantação, a partir de 2006, que resultaram na colação de grau da primeira turma de geólogos do estado e no reconhecimento do curso pelo Ministério de Educação, ambos em 2011. Atualmente o curso tem carga horária total de 4.410 h, integralização curricular em dez períodos semestrais, oferta anual de quarenta vagas e relação candidato/vaga no último vestibular em torno de nove; conta com doze docentes e dois servidores técnico-administrativos efetivos; tem cerca de duzentos estudantes matriculados em seis turmas e oriundos principalmente das seguintes mesorregiōes: Metropolitana de Vitória, Polo Cachoeiro e Caparaó no interior do estado do Espírito Santo e dos estados de Minas Gerais e Rio de Janeiro; a evasão média é de cerca de 30\% nas três primeiras turmas e de 10\% nas três turmas subsequentes; está instalado em prédio próprio com alguns laboratórios básicos em funcionamento e tem garantia de custeio integral das atividades de campo. As atuais condições de funcionamento do curso, em termos de atividades de ensino, pesquisa e extensão, sugerem que a futura autoavaliação e a atualização e revisão de seu projeto pedagógico devem auxiliar na sua consolidação em níveis estadual e regional.

PALAVRAS-CHAVE: Geologia, curso de graduação, Universidade Federal do Espírito Santo, Brasil 


\section{Introdução}

A fase inicial do curso de graduação em Geologia da Universidade Federal do Espírito Santo (UFES) pode ser dividida nas etapas de criação e de implantação do curso. A etapa de criação resultou de ações externas, de iniciativa do Governo Federal por meio do Ministério da Educação (MEC), e de ações internas, de responsabilidade da UFES por meio do seu Conselho Universitário (CUn/ UFES), ambas desenvolvidas ao longo do ano de 2005. A etapa de implantação compreendeu:

- a elaboração do Projeto Pedagógico do Curso (PPC), a instalação do Colegiado de Curso de Graduação (CCG) e o ingresso da primeira turma em 2006;

- o credenciamento e autorização para funcionamento do curso pelo MEC e a revisão do PPC em 2007;

- a aprovação do atual PPC e a definição do número de docentes efetivos diretamente vinculados ao curso em 2008;

- a instalação da Comissão Própria de Avaliação do Curso (CPAC) e a garantia de custeio integral pela UFES das atividades de campo e a aquisição de equipamentos básicos de laboratório e para atividades de campo em 2009;

- a conclusão das obras do prédio que abriga o curso e a disponibilização pelo MEC do restante de vagas para a efetivação de docentes em 2010;

- a instalação do Núcleo Docente Estruturante (NDE) do curso, a integralização curricular pelos estudantes periodizados da primeira turma, o reconhecimento do curso pelo MEC e a criação do Departamento de Geologia pela UFES em 2011; e

- a integralização curricular pelos estudantes desperiodizados da primeira turma, o cadastramento do curso no Conselho Regional de Engenharia, Arquitetura e Agronomia do Espírito Santo (CREA-ES) em 2012.

\section{Projeto pedagógico do curso}

$\mathrm{O}$ atual PPC de Geologia/UFES seguiu as recomendações da Secretaria de Educação Superior do MEC (SESu/MEC), quanto à adoção das Diretrizes Curriculares Nacionais (DCN), e da Pró-Reitoria de Graduação da UFES (PROGRAD/UFES), quanto à sua organização, e atende, na medida do possível, à necessidade de flexibilização do currículo e possibilidade de implantação de projeto pedagógico inovador, contemplando o perfil do profissional; suas competências, habilidades e atitudes; habilitações e ênfases; conteúdos curriculares; organização do curso; estágios e atividades complementares; e acompanhamento e avaliação do curso.

Considera que os estudos geológicos abordam a origem e evolução do planeta, incluindo a dos seres vivos que ocuparam seus continentes e mares e hoje se encontram preservados nas rochas, e buscam o entendimento sobre a composição das rochas; as estruturas geológicas; a gênese dos recursos minerais e energéticos que ocorrem na sub-superfície ou na superfície da crosta terrestre; as forças internas e externas naturais que moldam e alteram a superfície terrestre; e também sobre os possíveis efeitos das ações antrópicas sobre o Sistema Terra.

Ressalta que o bacharel em Geologia atua na exploração e extração de recursos minerais e energéticos, visando sua utilização de forma racional e seu melhor aproveitamento com redução de impactos ambientais; no planejamento e gestão territorial e ambiental, especialmente com relação aos recursos hídricos subterrâneos e ao uso do solo nos meios urbano e rural; e no diagnóstico de áreas de riscos geológicos e prevenção de catástrofes naturais ou artificiais induzidas pela ação antrópica.

\section{Justificativas}

A criação do curso de graduação em Geologia/UFES atendeu à política do Governo Federal de Expansão e Interiorização das Instituições de Ensino Superior (IES), executada pela SESu/MEC a partir de 2005, e ao Planejamento Estratégico/ UFES 2005-2010 e Plano de Expansão e Consolidação da Interiorização/UFES aprovados pelo CUn/UFES também em 2005.

A exigência de interiorização e a proximidade com a cidade de Cachoeiro de Itapemirim, maior pólo nacional de produção e beneficiamento de rochas ornamentais, resultaram na instalação do curso de Geologia/UFES na cidade de Alegre, alocado no Departamento de Engenharia Rural (ERU) do Centro de Ciências Agrárias (CCA/UFES).

Por outro lado, o importante pulso de desenvolvimento econômico verificado nos últimos anos no estado do Espírito Santo e acompanhado de forte incremento nos investimentos em infraestrutura, evidenciou sua histórica carência e crescente demanda por mão-de-obra especializada na área de Geociências. 


\section{Histórico}

A UFES é caracterizada desde seu início pela estrutura multicampi e foi criada em 1961 pela federalização da Universidade do Espírito Santo, instituição estadual criada em 1954 e composta por Escolas e Faculdades Isoladas de Ensino Superior criadas entre as décadas de 1930 e 1950.

A presença da UFES na cidade de Alegre tem início com a criação do Centro Agropecuário (CA/UFES) pela federalização em 1976 do curso de graduação em Agronomia da Escola Superior de Agricultura do Espírito Santo (ESAES), instituição estadual e criada em 1971.

O CA/UFES passou a se chamar Centro de Ciências Agrárias (CCA/ UFES) com a criação e implantação dos cursos de graduação em Engenharia Florestal, Medicina Veterinária e Zootecnia em 1999.

Como resultado da política de expansão e interiorização das IES os cursos de graduação em Ciências Biológicas, Engenharia de Alimentos, Engenharia Industrial Madeireira, Geologia e Nutrição foram implantados no CCA/UFES em 2006.

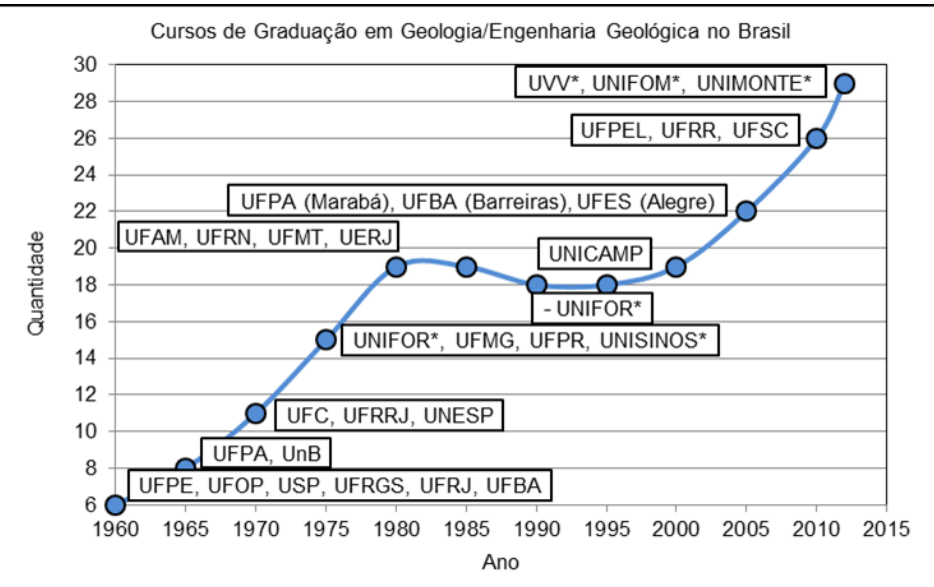

Figura 1. Evolução da quantidade de cursos de graduação em Geologia/ Engenharia Geológica no Brasil (*: instituições privadas)

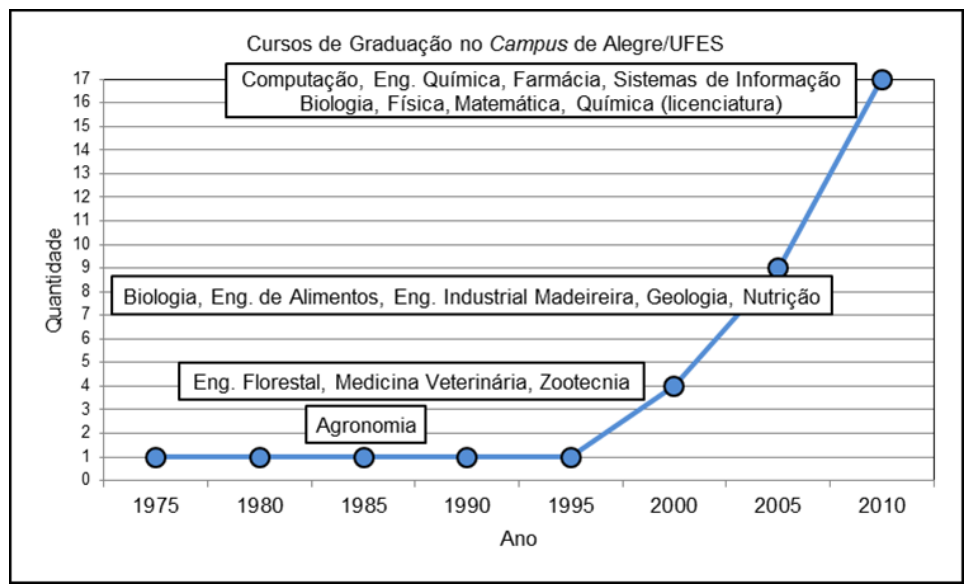

Figura 2. Evolução da quantidade de cursos de graduação no Campus de Alegre da Universidade Federal do Espírito Santo

A partir de 2007 o MEC deu início ao Programa de Apoio a Planos de Reestruturação e Expansão das Universidades Federais (REUNI), o que resultou na criação e implantação de mais sete cursos de graduação no CCA/UFES em 2009: bacharelados em Computação, Engenharia Química, Farmácia e Sistemas de Informação e licenciaturas em Ciências Biológicas, Física, Matemática e Química.

Desta forma, a criação e implantação do curso de Geologia/UFES acompanham a expansão dos cursos de Geologia/Engenharia Geológica no Brasil (Fig. 1) e demais cursos de graduação no Campus de Alegre/UFES (Fig. 2).

\section{Princípios norteadores}

$\mathrm{O}$ atual PPC de Geologia/UFES (Fortes et al., 2008) tem seus princípios norteadores baseados nos seguintes aspectos:

- as competências profissionais estabelecidas pela Lei Federal № 4.076/1962;
- o currículo mínimo definido pela Resolução CFE/MEC No 39/1975;

- as discussões e os estudos sistemáticos sobre o ensino de graduação em Geologia no Brasil promovidos pela Sociedade Brasileira de Geologia (SBG) (SBG 1982a, b e c, 1983);

- a Proposta de DCN elaborada pela sub-comissão de especialistas designada pelo MEC (Gomes et al., 1999);

- o campo de atuação profissional definido pela Resolução CONFEA No 1.010/2005;

- as discussões sobre as DCN realizadas pelo Fórum Nacional de Cursos de Geologia (Sobreira 2005, Carneiro 2005, Nummer et al. 2005, Carneiro et al. 2005, Fantinel et al. 2008);

- a análise do PPC inicial (Bastos et al., 2006); e

- a carga horária mínima estabelecida pela Resolução CNE/CES/MEC No 02/2007.

Desta forma, buscando a conciliação das abordagens das diretrizes curriculares e atribuições 
profissionais com as especificidades e limitações iniciais do curso, o atual PPC de Geologia/UFES tem como princípios norteadores a integração do conhecimento teórico com o treinamento prático intenso, em laboratório e trabalhos de campo, especialmente por meio de excursões didáticas e de atividades de mapeamento geológico, e a preparação do egresso para o desempenho profissional competente e a atuação social responsável.

\section{Objetivos}

$\mathrm{O}$ atual PPC de Geologia/UFES tem como objetivos gerais a flexibilização da aprendizagem dos estudantes e a orientação do CCG quanto aos fundamentos científicos da Geologia e às competências, habilidades e atitudes de seus profissionais.

Sua principal meta é o estabelecimento de estrutura curricular que possibilite a articulação entre os princípios norteadores adotados e o perfil profissional desejado dos egressos.

Os objetivos específicos visam fomentar:

- a visão abrangente das Geociências e das interações das Ciências Geológicas com as Ciências Exatas, Ambientais e Humanas;

- a abordagem qualitativa e quantitativa das informações geológicas e a familiaridade com métodos e técnicas de geoprocessamento;

- a formação de profissionais com aptidão e interesse por trabalhos de campo;

- o domínio da linguagem técnica geológica e a capacidade de adequação desta linguagem à comunicação com outros profissionais e com a sociedade; e

- a formação profissional de acordo com princípios éticos e legais.

\section{Perfil do profissional}

O PPC de Geologia/UFES procura seguir o perfil do profissional polivalente que desempenhe suas funções com competência técnica e responsabilidade social, em qualquer área de atuação profissional. A formação do geólogo deve, portanto, ter aspecto dinâmico e flexível, viabilizado por estrutura curricular que permita a adaptação de seus egressos às rápidas mudanças do mundo moderno.

Para tanto, foram consideradas:

- as competências legais do geólogo: trabalhos topográficos e geodésicos; levantamentos geológicos, geoquímicos e geofísicos; estudos relativos às ciências da terra; trabalhos de prospecção e pes- quisa para cubagem de jazidas e determinação de seu valor econômico; assuntos legais relacionados com suas especialidades; e perícias e arbitramentos referentes às matérias anteriores; $\mathrm{e}$

- o campo de atuação profissional no âmbito da Geologia/Engenharia Geológica e Engenharia de Minas : Topografia, Geodésia e Cartografia; Ciências da Terra e Meio Ambiente; Sistemas e Métodos de Geologia; Geologia de Engenharia e Geotecnia; Hidrogeologia e Hidrotecnia; Geologia Econômica, Prospecção e Pesquisa Mineral; Geologia de Hidrocarbonetos; e Lavra.

Visando ao desempenho de suas competências legais nos vários campos de atuação profissional e ao atendimento das exigências do mercado de trabalho e da sociedade, as seguintes habilidades são desejadas:

- execução de mapeamento geológico;

- formulação, elaboração, fiscalização e execução de estudos, planejamentos, projetos, pesquisas científicas básicas ou aplicadas e métodos ou técnicas visando ao melhor conhecimento e utilização racional dos recursos naturais terrestres;

- capacidade de otimização do aproveitamento tecnológico dos recursos minerais e energéticos com mínimo impacto ambiental;

- pesquisa de novas alternativas de exploração, conservação e gerenciamento de recursos hídricos;

- gestão ambiental, planejamento da ocupação urbana e previsão e prevenção de riscos de acidentes por desastres naturais e antrópicos; e

- ensino e pesquisa das Geociências tanto para a melhoria do desempenho profissional, como para a ampliação do conhecimento em geral.

Assim, espera-se que o profissional egresso atenda às demandas, especialmente em nível estadual, de mapeamento geológico sistemático em escalas de semi-detalhe e de detalhe; de pesquisa mineral nos setores de petróleo e gás natural, de rochas e minerais industriais e de rochas ornamentais; de aproveitamento de reservas de águas subterrâneas e bens minerais; de prevenção de catástrofes naturais e/ou decorrentes da ação antrópica, como erosão costeira, escorregamento de encostas e inundações; e de divulgação do conhecimento e de preservação do patrimônio geológico.

\section{Estrutura curricular}

A primeira versão curricular do PPC de Geologia/UFES foi aprovada em maio de 2006 pelo Conselho Departamental do CCA (CD/CCA) 
e, por não ter sido submetida à aprovação pelo Conselho de Ensino, Pesquisa e Extensão da UFES (CEPE/UFES), a implantação de sua grade curricular pela PROGRAD/UFES ocorreu parcialmente a partir do segundo semestre letivo de 2006 (2006/2) e a cada semestre letivo subsequente, pela oferta de disciplinas obrigatórias.

A necessidade de mudanças urgentes levou à elaboração do atual PPC, aprovado pelo CCG em Geologia em junho/2007, pelo CD/CCA em abril/2008 e pelo CEPE/UFES em dezembro/2008.

As três primeiras turmas do curso ingressaram no 2006/2, 2007/2 e 2008/1 com a primeira versão curricular do PPC (versão 2006) em vigência e concordaram com sua migração integral para a atual versão curricular do PPC (versão 2006/2), cuja nova grade curricular foi implantada pela PROGRAD/UFES a partir do 2008/2 e concluída no 2011/1, último período dos estudantes da primeira turma.

A integralização curricular ocorre em dez períodos, com duração mínima de cinco anos (dez semestres letivos) e máxima de sete anos (catorze semestres letivos) e carga horária total de 4.410 h $(22,5 \%$ além da carga horária mínima de 3.600 h).

As alterações no PPC de Geologia/UFES visaram à redução da carga horária $(\mathrm{CH})$ de disciplinas obrigatórias e do estágio supervisionado e ao aumento da carga horária do trabalho de conclusão e de disciplinas optativas (Tab. 1).

As disciplinas obrigatórias e optativas foram redefinidas quanto ao seu conteúdo (quadros 1 e 2); houve aumento da $\mathrm{CH}$ de atividades práticas (laboratório e campo) de disciplinas obrigatórias (Fig. 3); aumento da $\mathrm{CH}$ de disciplinas de conteúdo específico fundamental, disciplinas optativas e trabalho de
Tabela 1 - Comparação das etapas curriculares das versões inicial e atual do Projeto Pedagógico do Curso de Geologia/UFES

\begin{tabular}{c|c|c}
\hline Etapas curriculares & PPC Inicial & PPC Atual \\
\hline Disciplinas obrigatórias & $3.450 \mathrm{~h}$ & $3.210 \mathrm{~h}$ \\
\hline Disciplinas optativas & $300 \mathrm{~h}$ & $480 \mathrm{~h}$ \\
\hline $\begin{array}{c}\text { Trabalho de conclusão do } \\
\text { curso }\end{array}$ & $60 \mathrm{~h}$ & $300 \mathrm{~h}$ \\
\hline Estágio supervisionado & $360 \mathrm{~h}$ & $300 \mathrm{~h}$ \\
\hline $\begin{array}{c}\text { Atividades } \\
\text { complementares }\end{array}$ & $120 \mathrm{~h}$ & $120 \mathrm{~h}$ \\
\hline TOTAL & $4.290 \mathrm{~h}$ & $4.410 \mathrm{~h}$ \\
\hline
\end{tabular}

Quadro 1. Conteúdos, matérias e disciplinas obrigatórias do Curso de Geologia/UFES

\begin{tabular}{|c|c|c|}
\hline Conteúdo & Matéria & Disciplina obrigatória \\
\hline \multirow{13}{*}{ Básico Externo } & \multirow{3}{*}{ Matemática } & $\begin{array}{c}\text { Álgebra Linear e Geometria } \\
\text { Analítica }\end{array}$ \\
\hline & & Cálculo I \\
\hline & & Cálculo II \\
\hline & Estatística & Estatística Básica \\
\hline & Computação & $\begin{array}{c}\text { Lógica e Técnica de } \\
\text { Programação }\end{array}$ \\
\hline & \multirow{2}{*}{ Física } & Física I \\
\hline & & Física II \\
\hline & \multirow{3}{*}{ Química } & Química Básica \\
\hline & & Química Instrumental \\
\hline & & Físico-Química I \\
\hline & Biologia & Ecologia Básica \\
\hline & \multirow[b]{2}{*}{ Humanas } & Sociologia \\
\hline & & $\begin{array}{c}\text { Metodologia de Pesquisa e } \\
\text { Redação Científica }\end{array}$ \\
\hline
\end{tabular}

Quadro 2. Conteúdos, matérias e disciplinas optativas da grade curricular do Curso de Geologia/UFES

\begin{tabular}{|c|c|l|}
\hline Conteúdo & Matéria & Disciplina optativa \\
\hline \multirow{4}{*}{ Diverso } & Matemática & Cálculo III \\
\cline { 2 - 3 } & $\begin{array}{c}\text { Representações } \\
\text { Gráficas }\end{array}$ & Desenho Técnico \\
\cline { 2 - 3 } & Estatística & $\begin{array}{l}\text { Estatística } \\
\text { Experimental }\end{array}$ \\
\cline { 2 - 3 } & Computação & Informática \\
\cline { 2 - 3 } & Física & Física III \\
\cline { 2 - 3 } & Química & Química Orgânica \\
\cline { 2 - 3 } & Biologia & Ecologia \\
\hline
\end{tabular}

conclusão do curso e redução da $\mathrm{CH}$ de disciplinas de conteúdo básico externo e específico profissionalizante (Fig. 4); e redefinição da $\mathrm{CH}$, pré-requisitos e posicionamento na grade curricular de disciplinas obrigatórias (Fig. 5). 


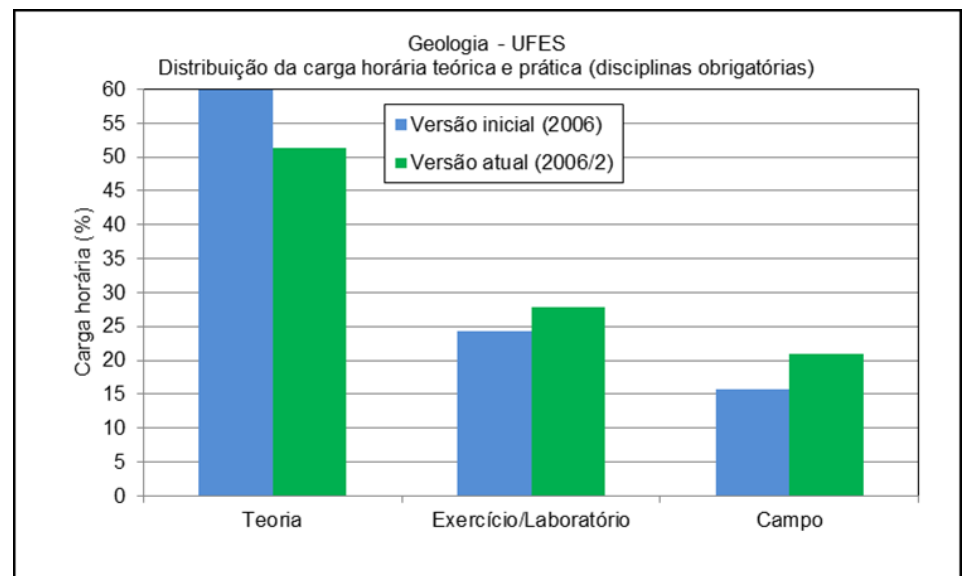

Figura 3. Comparação do percentual de carga horária das atividades teóricas, práticas de laboratório e práticas de campo das versões inicial e atual do PPC de Geologia/UFES

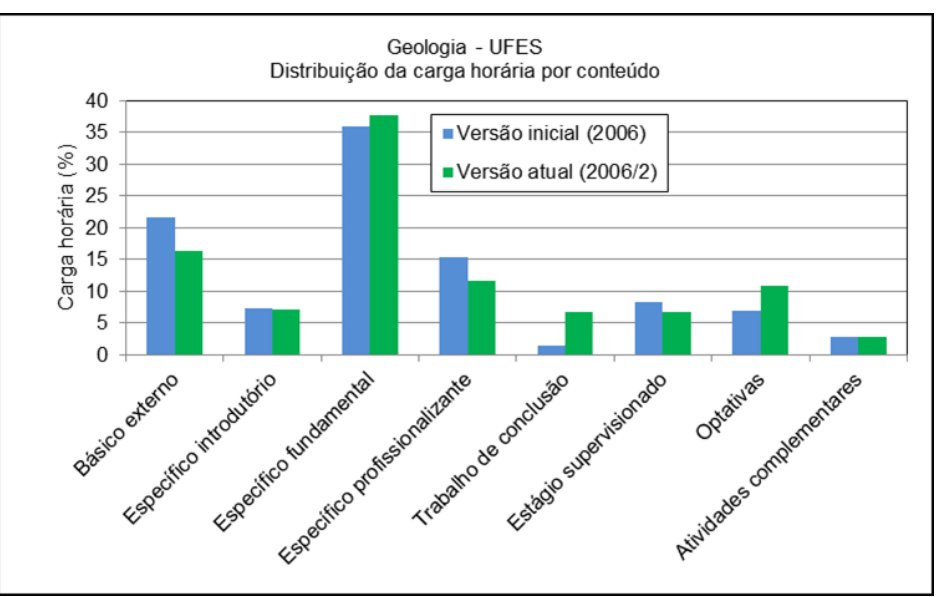

Figura 4. Comparação do percentual de carga horária por conteúdo das versões inicial e atual do PPC de Geologia/UFES

\section{Corpo Docente}

O curso de Geologia/UFES tem previsão de treze docentes efetivos diretamente a ele vinculados e as vagas foram disponibilizadas da seguinte forma: quatro no 2006/2, uma no 2008/2, quatro no 2009/1, três no 2009/2, uma no 2010/2.

Deve-se ressaltar que o docente efetivado no 2008/2 e três docentes efetivados no 2009/1 foram igualmente efetivados em outros cursos de Geologia (um em meados do 2009/1 e três no início do 2010/2) e que, desta forma, a reposição do quadro docente deu-se pela efetivação de três docentes no 2011/2 e será finalizada pela provável efetivação de um docente no 2012/2, por meio de concurso a ser realizado no 2012/1 (Fig. 6).

Atualmente, o quadro de docentes efetivados e vinculados diretamente ao curso tem onze docentes com graduação em Geologia/Engenharia Geológica e um em Engenharia de Agrimensura, sendo que 58,3\% têm doutorado e o restante está em doutoramento.

A maior parte do corpo docente tem graduação $(58,3 \%)$ e mestrado (75\%) obtidos na primeira década do século XXI e doutorado obtido ou a concluir (75\%) na primeira década do século XXI (Fig. 7) e a grande maioria dos docentes (75\%) tem graduação, mestrado e doutorado obtido ou a concluir em IES da Região Sudeste (Fig. 8).

$\mathrm{O}$ aumento progressivo da $\mathrm{CH}$ didática total em disciplinas obrigatórias e optativas sob responsabilidade dos docentes diretamente vinculados ao curso, exceto Seminário de Graduação e Estágio Supervisionado, foi acompanhado pelo aumento da quantidade de docentes efetivados, de maneira que a CH didática média semanal docente é de 11,2 h, com oscilações entre 8,3 h e 14,9 h (Fig. 9).

\section{Corpo Técnico-Administrativo}

O curso de Geologia/UFES tem apenas uma única servidora de nível técnico, com diploma de Técnico em Mineração e diretamente vinculada a ele, efetivada no 2008/2 e com redução de carga horária a partir do 2011/1 por ter ingressado como estudante no próprio curso.

Com a criação do Departamento de Geologia foi disponibilizada uma vaga para servidor administrativo, também de nível médio.

\section{Corpo Discente}

Para a primeira turma do curso de Geologia/ UFES foram oferecidas 25 vagas e a partir da segunda turma foram oferecidas 40 vagas (Tab. 2), sendo que ambas as turmas ingressaram no segundo semestre letivo (2006/2 e 2007/2, respectivamente), a partir da terceira turma (2008/1) o ingresso passou a ser no primeiro semestre letivo e a partir da quarta turma (2009/1) foi implantado o sistema de inclusão social com reserva $40 \%$ do total de vagas do curso destinados a estudantes que cursaram o Ensino Médio integralmente em escolas públicas do país. 


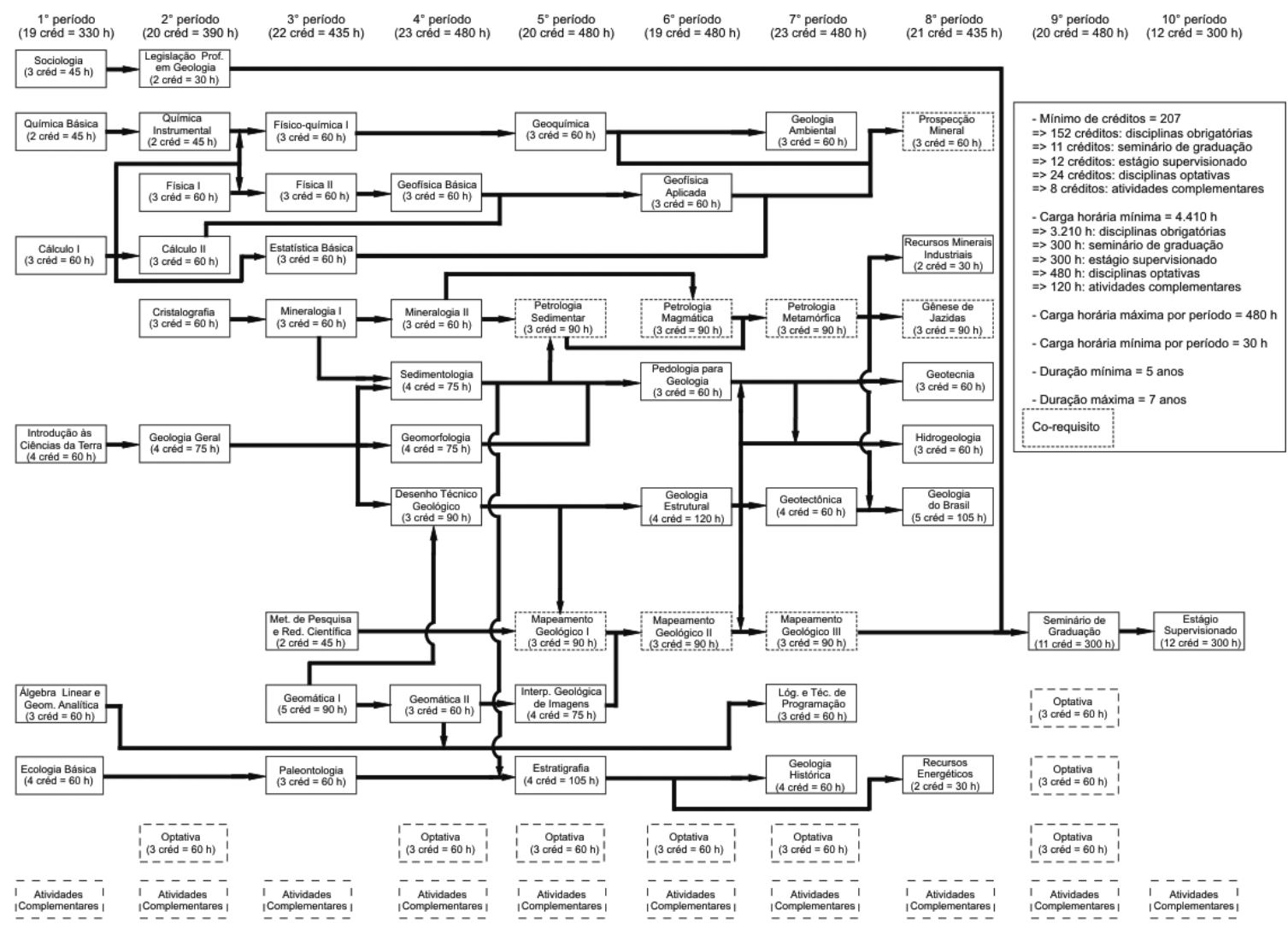

Figura 5. Fluxograma da grade curricular atual do curso de Geologia/UFES

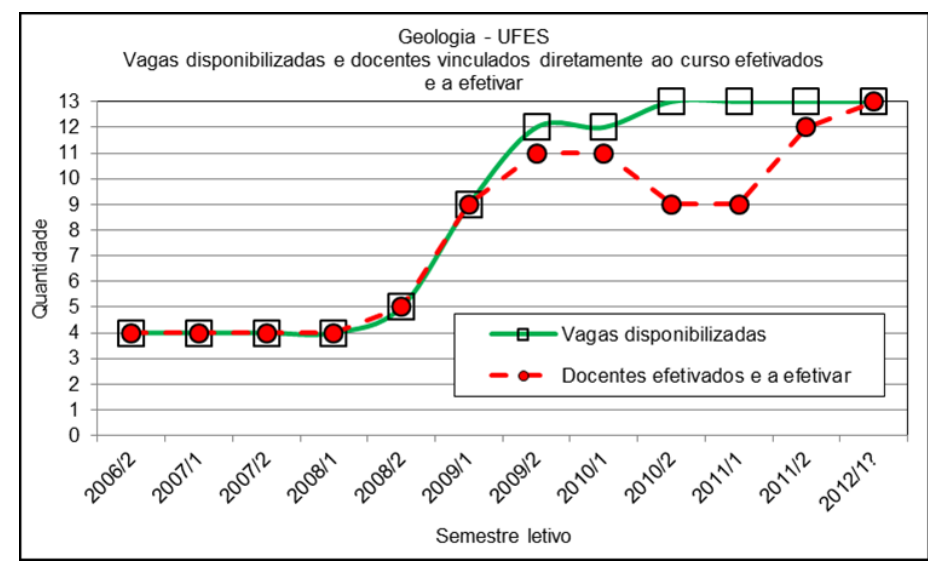

Figura 6. Vagas disponibilizadas e docentes efetivados e a efetivar e vinculados diretamente ao curso de Geologia/UFES

A relação candidato/vaga no vestibular, após a diminuição ocorrida pelo aumento de vagas e mudança no semestre letivo de ingresso, indica a crescente procura pelo curso (Tab. 2 e Fig. 10), sendo que, com exceção da turma com ingresso no $2008 / 1$, todas as demais turmas têm tido saldo de vagas abaixo de $10 \%$, e a evasão média é de $21,8 \%$, com tendência de queda (Tab. 2 e Fig. 11).
O perfil sócio-econômico de estudantes do curso de Geologia/ UFES, incluindo a primeira turma, revela que:

- em sua maioria são jovens solteiros $(98 \%)$, do sexo masculino $(61,6 \%)$, que se declaram brancos $(64,3 \%)$, sem atividade remunerada (79,2 \%), sem participação na renda familiar $(83,7 \%)$ e frequentam o primeiro curso superior $(81,6 \%)$;

- provêm de escolas particulares em níveis fundamental $(65,3 \%)$ e médio $(71,5 \%)$;

- não fizeram $(36,0 \%)$, fizeram por menos de um semestre $(15,1 \%)$, por um semestre $(12,7 \%)$, por um ano $(19,9$ $\%)$ ou por mais de um ano $(15,0 \%)$ curso pré-vestibular;

- fizeram vestibular pela primeira vez $(17,5 \%)$, uma vez $(32,7 \%)$, duas vezes $(22,7$ $\%)$, três vezes $(11,6 \%)$ ou quatro vezes $(14,2 \%)$;

- não fizeram vestibular na UFES (48,0 \%) ou fizeram uma vez $(29,4 \%)$, duas vezes $(15,0 \%)$ ou três vezes $(5,3 \%)$; 


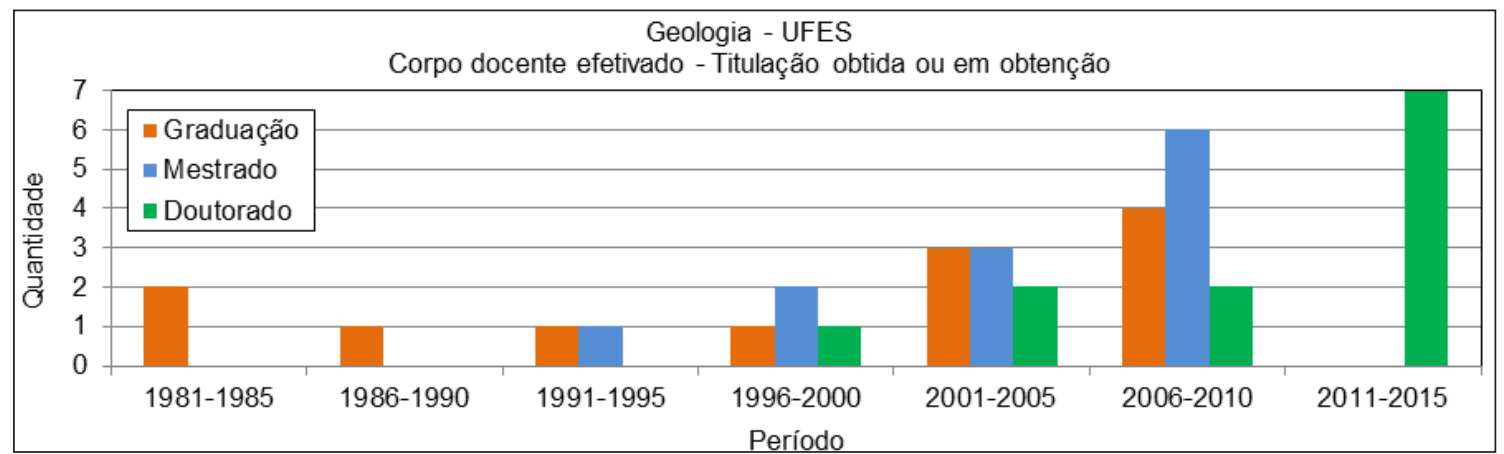

Figura 7. Períodos de titulação obtida ou em obtenção de docentes efetivados e vinculados diretamente ao curso de Geologia/UFES

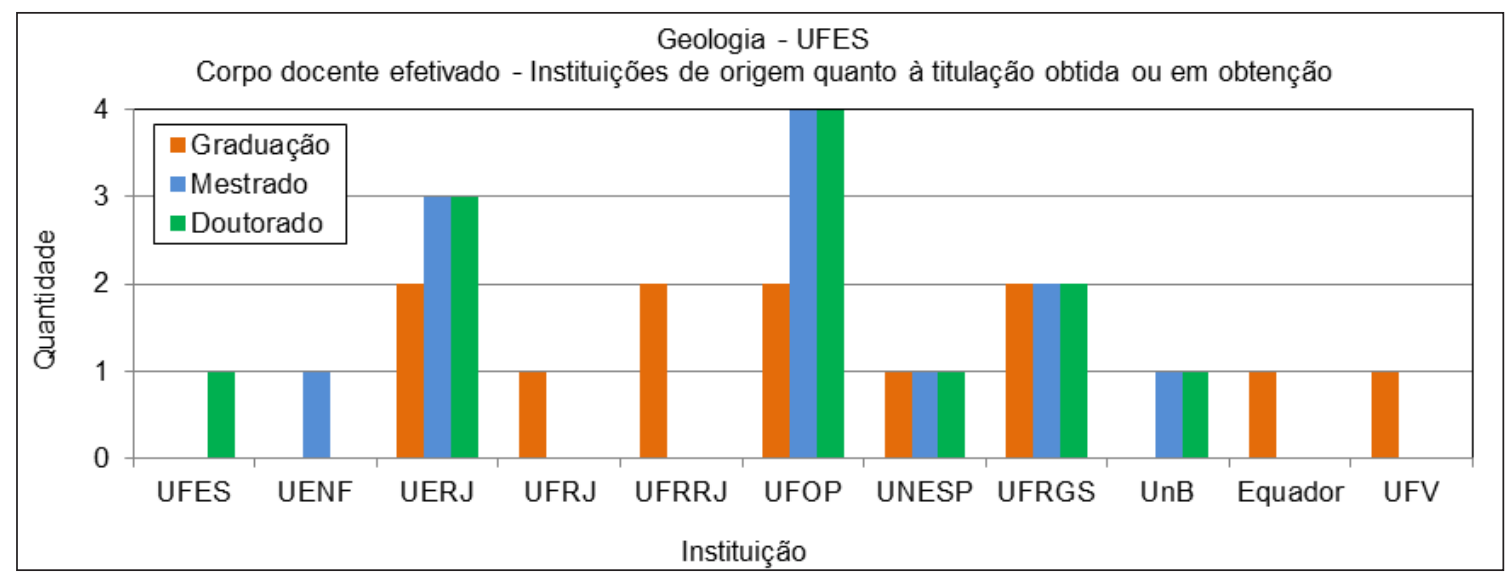

Figura 8. Instituições de origem quanto à titulação obtida ou em obtenção de docentes efetivados e diretamente vinculados ao curso de Geologia/UFES

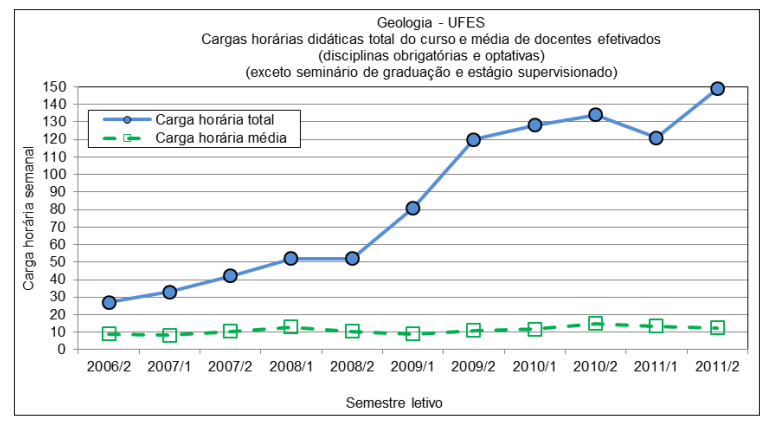

Figura 9. Cargas horárias didáticas total do curso e média semanal dos docentes efetivados e diretamente vinculados ao curso de Geologia/UFES

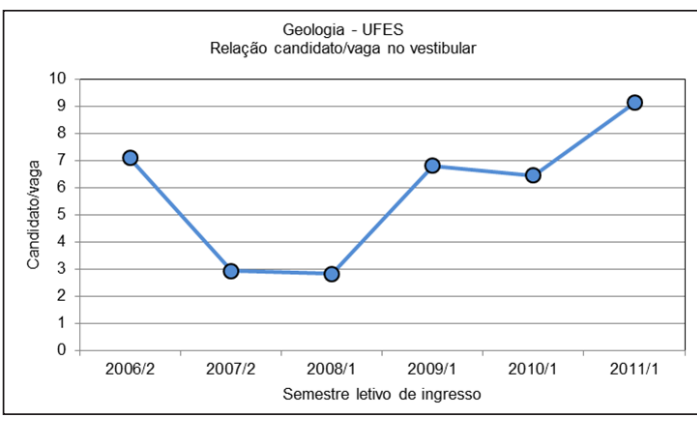

Figura 10. Relação candidato/vaga no vestibular por semestre letivo de ingresso no curso de Geologia/ UFES

Tabela 2. Vagas oferecidas, relação candidato/vaga, candidatos aprovados no vestibular, saldo de vagas, estudantes matriculados e evasão de estudantes por semestre letivo de ingresso no Curso de Graduação em Geologia/UFES

Vagas oferecidas

Candidato/vaga no vestibular Candidatos aprovados no vestibular Saldo de vagas

Estudantes matriculados no curso (2011/2) Evasão (\%)

\begin{tabular}{c|c|c|c|c|c}
$\mathbf{2 0 0 6 / 2}$ & $\mathbf{2 0 0 7 / 2}$ & $\mathbf{2 0 0 8 / 1}$ & $\mathbf{2 0 0 9 / 1}$ & $\mathbf{2 0 1 0 / 1}$ & $\mathbf{2 0 1 1 / 1}$ \\
25 & 40 & 40 & 40 & 40 & 40 \\
7,1 & 2,9 & 2,8 & 6,8 & 6,4 & 9,1 \\
25 & 40 & 26 & 40 & 37 & 37 \\
0 & 0 & 24 & 0 & 3 & 3 \\
22 & 29 & 14 & 35 & 33 & 37 \\
12,0 & 27,5 & 46,2 & 12,5 & 10,8 & - \\
\hline
\end{tabular}




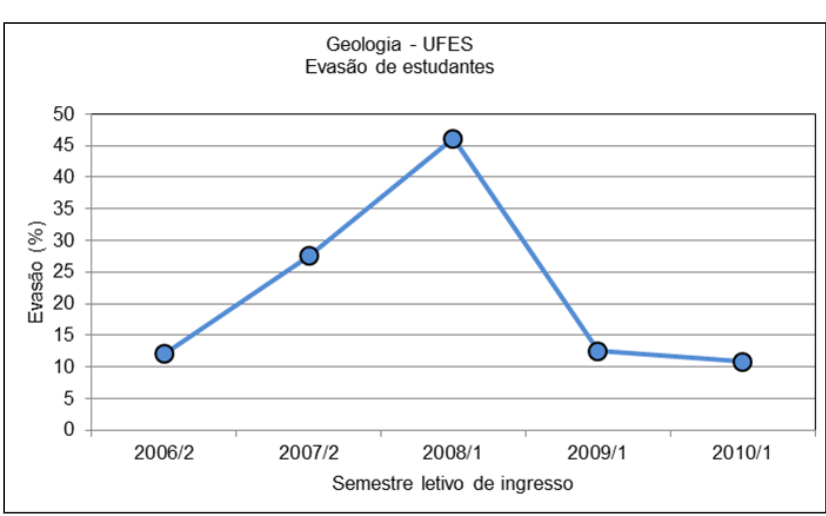

Figura 11. Evasão de estudantes por semestre letivo de ingresso no curso de Geologia/UFES

- buscam melhor compreensão do mundo (8,5\%), melhor nível de instrução (11,4\%), qualificação profissional $(65,5 \%)$ ou formação para a pesquisa $(6,5 \%)$

- escolheram o curso por aptidão vocacional $(47,8 \%)$ ou possibilidade de emprego (23,3\%);

- são provenientes de famílias com renda mensal de até $3(11,5 \%)$, de 3 a $5(26,3 \%)$, de 5 a $10(31,2 \%)$, de 10 a $15(18,5 \%)$ ou de 15 a 20 (5,8\%) salários mínimos; com 3 (13,7\%), 4 (42,8 $\%)$ ou $5(23,6 \%)$ pessoas; com instrução paterna de nível médio $(28,9 \%)$ ou superior $(38,5 \%)$ completos e materna de nível médio $(32,7 \%)$ ou superior $(32,1 \%)$ completos; e com pais $(78,4$ $\%)$ e mães $(75,4 \%)$ profissionalmente ativos;

- têm residência de origem, principalmente, no estado do Espírito Santo, especialmente nas microrregiões administrativas Metropolitana da Grande Vitória (38,3 \%), Pólo Cachoeiro (13,8 $\%)$, Caparaó (11,0 \%) e Litoral Norte (3,5\%), e em Minas Gerais (15,6\%), Rio de Janeiro (4,0 \%) e São Paulo (2,7 \%) (Fig. 12).

\section{Acompanhamento e avaliação do Curso}

Para a implantação da expansão e consolidação do CCA foi prevista a contratação de 80 docentes (20 em 2006, 40 em 2007 e 20 em 2008) e de 40 técnicos em educação, além de investimento em obras $(\mathrm{R} \$ 7.124 .903,00)$, reformas $(\mathrm{R} \$ 1.375 .000,00)$, bens permanentes $(\mathrm{R} \$ 2.430 .097,00)$ e custeio $(\mathrm{R} \$$ $876.000,00)$, em três etapas ( $\mathrm{R} \$ 3.000 .000,00 \mathrm{em}$ 2006, R \$ 3.000.000,00 em 2007 e R \$ 5.806.000,00 em 2008).

Para o curso de Geologia/UFES, foi aprovado pela Financiadora de Estudos e Projetos/Fundo Setorial de Infra-Estrutura (FINEP/CT-INFRA/ NOVOS CAMPI-2006), projeto no valor de $\mathrm{R} \$$ 412.000,00.

Entretanto, a partir do 2007/1 e, especialmente ao longo de 2008, o CCG em Geologia, composto por três docentes do próprio curso, um docente representante do departamento, dois docentes representantes de outros departamentos que ministram aulas ao curso e um representante discente, enviou diversos memorandos às instâncias administrativas (Chefia/ERU, Direção/CCA, Pró-Reitorias e Reitoria/UFES) alertando sobre a urgência de atendimento das necessidades básicas de funcionamento do curso visando à adequada formação profissional dos estudantes.

As maiores dificuldades na implantação do curso foram quanto à aprovação do atual PPC, efetivação do quadro docente, construção do prédio, aquisição de equipamentos para o laboratório de microscopia e custeio integral das atividades de campo.

Para a aprovação do atual PPC no 2008/2, foi necessário o apoio da Comissão de Ensino de Graduação e Extensão (CEGE/CEPE/UFES), no âmbito interno, e do Fórum Nacional de Cursos de Geologia e da Executiva Nacional dos Estudantes de Geologia (ENEGE), no âmbito externo.

Também no 2008/2, foi definido o número total de 13 docentes efetivos diretamente vinculados ao curso, resultado da solicitação de esclarecimentos quanto aos critérios para a efetivação de docentes que motivaram os estudos de comissão responsável pela Proposição de Metodologia Para Cálculo de Demanda de Professores do CCA/UFES.

No 2009/1, a avaliação interna pela CPAC, composta pelo coordenador, um
Figura 12. Residência de origem de estudantes por semestre letivo de ingresso no curso de Geologia/UFES 
docente, um servidor técnico e um discente do curso, como membros internos, e um representante do setor produtivo (PETROBRAS) e um membro representante de associação de classe (SBG-RJ), como membros externos, resultou em relatório encaminhado à Direção/CCA, PROGRAD/UFES e Ouvidoria/UFES, no qual se destacaram:

- como aspectos favoráveis: a adequação do atual PPC, a boa qualificação dos docentes efetivados e seu esforço em atuar nas atividades de ensino, pesquisa e extensão e o efetivo envolvimento do corpo discente na tentativa de buscar soluções para os problemas observados; e

- como aspectos desfavoráveis: a alta carga horária didática docente, o aumento do desestímulo dos estudantes e as carências de infraestrutura física, administrativa e financeira.

Até então não havia sido construído o prédio da Geologia, previsto para o 2007/1 com recursos financeiros da expansão e interiorização, não havia sido adquirido nenhum equipamento com recursos financeiros do CT-INFRA, ainda que os mesmos tivessem sido disponibilizados pela FINEP no 2007/1, e não havia custeio por parte da UFES das atividades de campo, desenvolvidas com recursos financeiros próprios de docentes e discentes.

Desta maneira, a situação do curso tornou-se insustentável:

- os estudantes fizeram manifestações, entraram em greve, acamparam em frente à Direção/CCA e apresentaram denúncia ao Ministério Público Federal, com base nos memorandos enviados pelo CCG às instâncias administrativas superiores da UFES; e

- os docentes decidiram paralisar as atividades de ensino por falta de condições mínimas de funcionamento do curso.

Tais ações resultaram em termo de compromisso firmado pela Reitoria/UFES garantindo o custeio integral das atividades de campo por parte da UFES a partir do 2009/1, a aquisição dos equipamentos com recursos do CT-INFRA, iniciada no 2009/1 e finalizada no 2010/1, e a conclusão das obras do prédio da Geologia com dois andares e área total de cerca de $700 \mathrm{~m}^{2}$, também no 2010/1.

A solicitação de reconhecimento do curso pelo MEC foi feita no 2009/2 e o Núcleo Docente Estruturante (NDE) do curso foi instalado no 2010/1, atendendo à Resolução CONAES/MEC 01/2010, com a seguinte composição: coordenador do curso e três docentes mais antigos e que participaram da elaboração do atual PPC.
A avaliação in loco do curso pela comissão de especialistas do MEC no 2010/2, resultou em nota final 4 (arredondamento da média 3,6, sendo a nota máxima igual a 5), com destaque para os seguintes aspectos:

- organização didática pedagógica: implementação de forma suficiente das políticas institucionais constantes do Plano de Desenvolvimento Institucional/UFES no âmbito do curso, auto-avaliação pela CPAC como instrumento eficiente na implantação de ações acadêmicas e administrativas que proporcionaram melhoria do curso, matriz curricular com carga horária que permite o pleno desenvolvimento dos conteúdos curriculares, coerente com o perfil do egresso e compatível com as demandas do mercado de trabalho atual e mobilização suficiente do corpo docente para trabalhos de campo, laboratório e participação em eventos científicos, mas questões burocráticas e administrativas vinculadas à gestão institucional como aspectos que dificultam o pleno atendimento aos objetivos previstos no PPC (conceito: 3 );

- corpo docente: titulação e formação acadêmica do NDE adequada, funcionamento do CCG representativo e importante nas decisões sobre assuntos acadêmicos do curso, totalidade de docentes com titulação obtida em programas de pós-graduação stricto sensu e efetivados em regime de tempo integral, $75 \%$ dos docentes com, no mínimo, quatro anos de experiência acadêmica no ensino superior (conceito: 4); e

- instalação física: salas de professores, de reuniões e de aulas adequadas, registro acadêmico informatizado implantado, confiável e eficiente, acervo de títulos da bibliografia básica e complementar das disciplinas do curso em quantidade suficiente, assinaturas de periódicos especializados atualizados em sua maioria nos últimos três anos, abrangendo as principais áreas temáticas e distribuídas entre as principais áreas do curso, laboratórios especializados para a realização das aulas práticas com infraestrutura suficiente para o atendimento às demandas do curso (conceito: 4).

O cadastramento do curso no CREA-ES foi solicitado em fevereiro de 2011, a colação de grau da primeira turma de geólogos do estado do Espírito Santo (12 estudantes periodizados) ocorreu em julho/2011e o curso foi reconhecido pelo MEC em novembro/2011, conforme a Portaria MEC N ${ }^{\circ}$ 446/2011.

Por fim, em fevereiro/2012 houve a colação de grau de 5 estudantes desperiodizados da primeira 
turma, o cadastramento do curso no CREA-ES foi aprovado em abril/2012 e a Câmara Departamental do Departamento de Geologia foi instalada em maio/2012.

\section{Discussão e conclusões}

A criação do curso de Geologia/UFES ocorreu em momento extremamente favorável em níveis internacional, nacional, regional e estadual, considerando, por um lado, o aumento da demanda por recursos minerais e energéticos em todos os níveis e o crescimento econômico do estado do Espírito Santo, com o consequente aquecimento do mercado de trabalho; e, por outro, as ações do Governo Federal e a participação da UFES visando à expansão, interiorização e reestruturação das IES.

Entretanto, sua implantação foi e/ou ainda vem sendo dificultada por fatores essencialmente administrativos, tais como:

- por parte do Governo Federal, os atrasos na execução do cronograma de disponibilização de recursos financeiros e de vagas para efetivação de docentes e técnico-administrativos: percebe-se em nível nacional que os recursos financeiros para a expansão, interiorização e reestruturação das IES são insuficientes e que sua liberação está sujeita à política orçamentária do país;

- por parte da UFES, o isolamento do curso no Campus de Alegre/UFES, como único curso na área de Geociências no sul do estado, e a falta de otimização de recursos financeiros e humanos, decorrente da criação à mesma época do curso de graduação em Engenharia do Petróleo no Campus de São Mateus/UFES, no norte do estado, e, posteriormente, do curso de graduação em Gemologia no Campus de Goiabeiras, em Vitória; a centralização excessiva nas instâncias e colegiados superiores quanto às decisões administrativas e acadêmicas, especialmente em relação à aplicação de recursos financeiros: a maior autonomia para o Campus de Alegre poderia diminuir o tempo de tramitação de processos administrativos, de procedimentos acadêmicos rotineiros e de aplicação dos recursos financeiros;

- por parte do CCA/UFES: pouca transparência na definição de critérios adotados na aplicação dos recursos financeiros destinados para investimento em custeio, obras e reformas, aquisição de material permanente e equipamentos e efetivação de docentes e técnico-administrativos: a criação de novos centros no Campus de Alegre, como o de Ciências
Exatas e da Terra, que agreguem departamentos e cursos afins poderia contribuir para que suas necessidades básicas de funcionamento fossem diretamente encaminhadas para a administração central;

- por parte do ERU/CCA, as limitações quanto à compreensão das necessidades básicas de funcionamento do curso: a esperada implantação do Departamento de Geologia certamente contribuirá para que as demandas básicas do curso sejam devidamente discutidas no âmbito do Campus de Alegre e encaminhadas para a administração central;

- por parte do CCG, NDE e CPAC, a excessiva centralização das atividades acadêmicas no coordenador do curso: a maior quantidade de docentes efetivos diretamente vinculados ao curso poderá resultar na melhor divisão de tarefas em termos de distribuição de carga horária didática e acompanhamento e avaliação do curso.

Por outro lado, quanto aos aspectos diretamente relacionados ao PPC, pode-se destacar que:

- a partir da criação e implantação do curso de Geologia/UFES, foi formada a primeira turma de geólogos(as) do estado do Espírito Santo e houve significativo aumento no desenvolvimento de atividades de pesquisa e extensão na área de Geociências em níveis estadual e municipal;

- as avaliações do curso pela CPAC e pelo MEC e a atuação do NDE são importantes instrumentos de acompanhamento, pois possibilitam a sistemática reflexão e a permanente verificação de avanços e detecção de deficiências ainda não superadas;

- o custeio integral das atividades de campo resultou no atendimento de tais demandas de diversos cursos e na aquisição de mais veículos para o Campus de Alegre e também no pagamento do seguro de vida dos estudantes pela UFES;

- o desenvolvimento de projetos de pesquisa e extensão com recursos financeiros externos possibilitou a aquisição de mais equipamentos laboratoriais e de material didático, além do maior envolvimento de estudantes;

- a renovação do quadro docente, se por um lado dificulta o estabelecimento das tendências do curso quanto às linhas de pesquisa e extensão, por outro lado, constitui oportunidade para o ingresso de docentes ainda em doutoramento e que, por motivos pessoais e/ou profissionais se sintam estimulados a permanecer no curso;

- a efetivação de servidor administrativo e a melhoria das condições de funcionamento de laboratórios reforçarão a necessidade de aumento quantitativo do corpo técnico-administrativo; 
- o aumento da relação candidato/vaga e a diminuição da evasão indicam que o funcionamento do curso atende, na medida do possível, às expectativas básicas dos estudantes;

- o aumento no ingresso de estudantes do interior do estado do Espírito Santo indica que o objetivo de interiorização está sendo atingido, e a presença de estudantes de estados vizinhos, principalmente de Minas Gerais e do Rio de Janeiro, que o curso está contribuindo para atender à alta demanda atual do mercado de trabalho em níveis nacional e estadual;

- a contabilização da carga horária de atividades complementares e estágio supervisionado obrigatório, se por um lado, aumenta a carga horária total do curso, por outro, incentiva e dá oportunidade aos estudantes para que busquem a complementação de sua formação profissional por meio de atividades de pesquisa e extensão e contato com o mercado de trabalho.

A revisão e atualização do PPC de Geologia/ UFES foram iniciadas pelo CCG e NDE, assim como a segunda avaliação pela CPAC, no 2012/1 e a expectativa é que o levantamento das informações seja o mais próximo possível da atual realidade do curso em termos de corpos docente, técnico-administrativo e discente de infraestrutura física e didática, para que a nova grade curricular, com os necessários ajustes e a ser implantada provavelmente no 2014/1, seja compatível com a realidade do curso e auxilie na sua consolidação em níveis estadual e regional, especialmente quanto à melhoria das condições de ensino-aprendizagem, ao incentivo à permanência de docentes efetivados e ingresso e permanência de estudantes.

\section{Referências bibliográficas}

Bastos A.C., Passos R.R., Albino J. 2006. Projeto Pedagógico do Curso de Graduação em Geologia. Centro de Ciências Agrárias, Universidade Federal do Espírito Santo, Alegre. 111p. (inédito).

Carneiro C.D.R., Nummer A.R., Assis J.F.P., Pinho F.E.C. 2005. Relato Final do III Encontro do Fórum Nacional de Cursos de Geologia. Terra Didatica, 1(1):84-96. <http://www.ige.unicamp. $\mathrm{br} /$ terraedidatica/>
Fantinel L., Janasi V.A., Assis J.F.P., Alecrim J.R., Almeida H.L.de, Compiani M., Conceição R., Duarte B.P., Fauth G., Fonseca V.P.da, Fortes P.T.O.F., Leite Júnior W.B., Mancini F., Menezes M.G.de, Silva C.H.da, Silva Filho W., Velloso E., Carneiro C.D.R. 2008. Diretrizes curriculares para os cursos de graduação em Geologia e Engenharia Geológica. Terre Didatica, 4(1):85-89 < http://www. ige.unicamp.br/terraedidatica/>

Gomes N.S., Landim P.M.B., Fuck R.A. 1999. Diretrizes Curriculares para os Cursos de Graduação em Geologia e Engenharia Geológica. Ministério da Educação, Brasília. 7p. (inédito).

Nummer A.R., Godoy A.M., Lazzarotto A., Carneiro C.D.R., Schultz C.L., Tubbs Filho D., Guimarães E.M., Althoff F., Assis J.F.P., Pinho F.E.C., Sobreira F., Carvalho I.S., Sabadia J.A.B., Fernandes Filho L.A., Toledo M.C.M.de, Fernandes M.L.S., Costa R.D.da, Machado R., Menegat R., Nadalin R.J., Santos R.A.A.dos, Vasconcelos S.M.S., Marques T.M., Souza Z.S. 2005. Diretrizes Curriculares para os Cursos de Graduação em Geologia e Engenharia Geológica. Terre Didatica, 1(1):64- 69. < http:// www.ige.unicamp. $\mathrm{br} /$ terraedidatica/ $>$

Rangel C.V.G.T., Lana C.E., Neves M.A., Fortes P.T.F.O. 2008. Projeto Político-Pedagógico do Curso de Graduação em Geologia. Centro de Ciências Agrárias, Universidade Federal do Espírito Santo, Alegre, $174 p$. (inédito)

SBG 1982a. A Formação do Geólogo nas Universidades Brasileiras. Um retrato de duas décadas. Sociedade Brasileira de Geologia, São Paulo. 225p.

SBG 1982b. Simpósio Nacional: o Ensino de Geologia no Brasil, Teses (volumes I e II). Sociedade Brasileira de Geologia, Belo Horizonte. 268p.

SBG 1982c. Simpósio Nacional: o Ensino de Geologia no Brasil, Documento Final. Sociedade Brasileira de Geologia, Belo Horizonte. 155p.

SBG 1983. II Simpósio Nacional: o Ensino de Geologia no Brasil. Documento Final, Currículo Mínimo. Sociedade Brasileira de Geologia, Salvador. 73p.

Sobreira F. 2005. Relato Final do I Seminário Nacional sobre Cursos de Graduação em Geologia. Terra Didatica, 1(1):51-54. < http://www.ige.unicamp. $\mathrm{br} /$ terraedidatica/ $>$ 